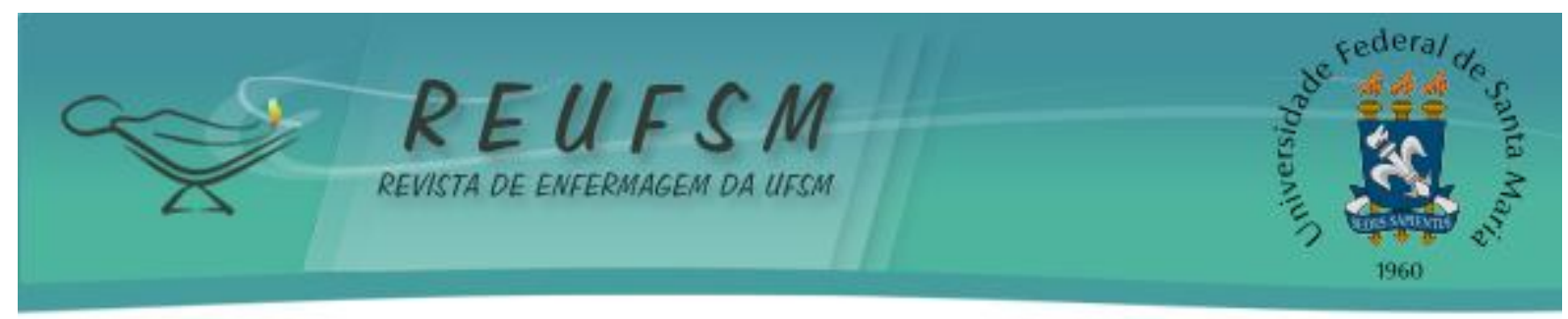

ARTIGO ORIGINAL

\title{
GRUPO DE FAMILIARES DE UM CENTRO DE ATENÇÃO PSICOSSOCIAL: EXPERIÊNCIAS DE SEUS USUÁRIOS
}

\section{GROUP OF RELATIVES OF A PSYCHOSOCIAL CARE CENTER: EXPERIENCES OF THE USERS \\ GRUPO DE FAMILIARES DE UN CENTRO DE ATENCIÓN PSICOSOCIAL: EXPERIENCIAS DE LOS USUARIOS}

\author{
Juliane Portella Ribeiro ${ }^{1}$ \\ Valéria Cristina Christello Coimbra² \\ Anelise Miritz Borges ${ }^{3}$
}

RESUMO: Objetivo: compreender a diversidade de experiências dos familiares da pessoa em sofrimento mental dentro do grupo de familiares. Método: estudo qualitativo, exploratório e descritivo realizado no domicílio de cinco pessoas participantes há no mínimo seis meses do Grupo de Familiares dirigido pelo CAPS. A coleta dos dados ocorreu em novembro e dezembro de 2009, utilizando entrevistas semiestruturadas. Resultados: a participação do familiar no cuidado requer sua corresponsabilidade à construção de vínculos no grupo e expressão de sentimentos e dúvidas, construindo confiança para obter a satisfação com a prática assistencial. Conclusão: os familiares solicitam acolhimento, escuta e ajuda para administrar a convivência com a pessoa em sofrimento mental, otimizando a troca e aprendizagem de saberes através da ação grupal.

Descritores: Enfermagem; Família; Saúde mental; Desinstitucionalização.

ABSTRACT: Objectivo: understand the different experiences of the relatives of the person in mental suffering within the family group. Methodology: a qualitative, exploratory and descriptive study, carried out in the domicile of five participants, which are engaged for a minimum period of six months in the Family Group administered by CAPS. The data collection took place in the months of November and December of the year 2009, using semi-structured surveys. Results: the participation of the family in the caring demands their co-responsibility in the formation of connections and in the expression of feelings and doubts among the familial group, building trust to obtain satisfaction with the caring practice. Conclusion: the relatives request the embracement, the listening and the helping to manage the living with the person in mental suffering, optimizing the exchanging and learning of knowledge through the group action.

Descriptors: Nursing; Family; Mental health; Deinstitutionalization.

RESUMEN: Objetivo: comprender las diferentes experiencias de los familiares de la persona con sufrimientos mentales en el grupo familiar. Método: estudio cualitativo, exploratorio y descriptivo realizado en el hogar de cinco integrantes, por lo menos seis meses, del grupo familiar dirigido por el CAPS. La recolección de datos tuvo lugar entre noviembre y diciembre de 2009, con entrevistas semi-estructuradas. Resultados: la coparticipación de la familia en

\footnotetext{
${ }^{1}$ Enfermeira. Psicóloga. Especialista em Saúde Mental no Contexto Multidisciplinar. Doutoranda do Programa de Pós-Graduação em Enfermagem da Universidade Federal do Rio Grande (FURG). Membro do Grupo de Estudo e Pesquisas de Família, Enfermagem e Saúde (GEPEFES). Rio Grande (RS), Brasil. E-mail: ju_ribeiro1985@hotmail.com

${ }^{2}$ Enfermeira. Professora Doutora da Faculdade de Enfermagem da Universidade Federal de Pelotas. E-mail: valeriacoimbra@hotmail.com

${ }^{3}$ Enfermeira. Doutoranda do Programa de Pós-Graduação em Enfermagem da Universidade Federal do Rio Grande (FURG). Membro do Laboratório de Estudos de Processos Socioambientais e Produção Coletiva de Saúde (LAMSA). Rio Grande (RS), Brasil. Bolsista CAPES/REUNI. E-mail: miritzenfermeira@yahoo.com.br
} 


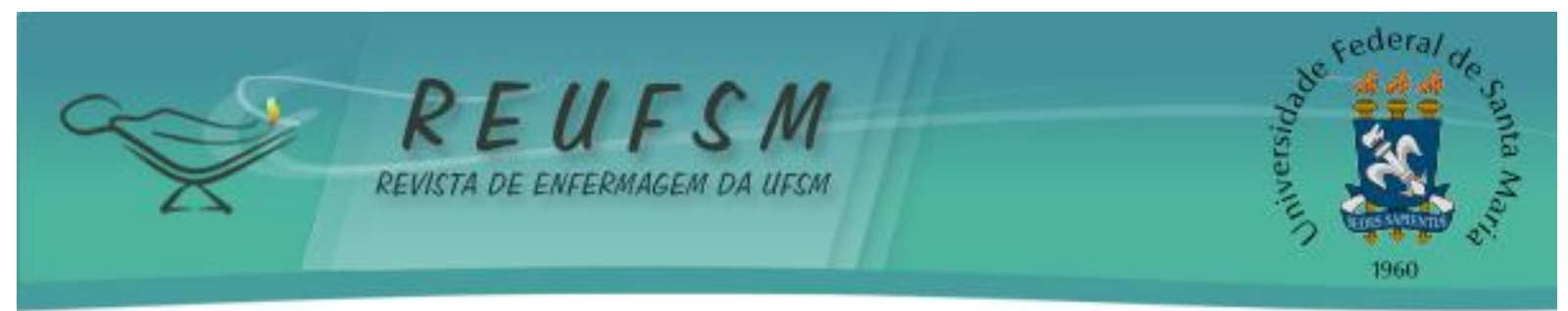

el cuidado requiere su corresponsabilidad para establecer vínculos en el grupo y expresar sus sentimientos y preocupaciones, construyendo la confianza para obtener satisfacción con la práctica de ayuda. Conclusión: la familia solicita la acogida, escucha y ayuda para la gestión de vivir con la persona con sufrimientos mentales, optimizando el intercambio de conocimientos y el aprendizaje mediante la acción de grupo.

Descriptores: Enfermería; Familia; Salud mental; Desinstitucionalización.

\section{INTRODUÇÃO}

As práticas em saúde mental anteriores à Reforma Psiquiátrica eram marcadas por internações em hospitais psiquiátricos e asilos manicomiais e, consequentemente a exclusão do convívio social dos "doentes" como eram denominadas as pessoas em sofrimento mental. Estas eram consideradas com uma conduta desviante, perigosa e indesejável pela sociedade.

No final da década de 70, essa forma de se classificar e tratar a condição passou a ser questionada por profissionais da área da saúde mental, familiares e pacientes, dando origem ao movimento da Reforma Psiquiátrica. Este surgiu com objetivos que transcendiam a humanização de hospícios, melhoria do ambiente dos manicômios e ampliação do número de profissionais nessas instituições. A proposta era/é a reintegração social da pessoa em sofrimento mental, deslocando o tratamento para a comunidade e dinâmica familiar. ${ }^{1}$

Para alcançar os objetivos do movimento reformista foi necessário criar novos dispositivos em substituição aos manicômios. Dentre os diferentes serviços substitutivos, destacam-se os Centros de Atenção Psicossocial (CAPS), as unidades de atenção básica, as residências terapêuticas, os ambulatórios, os centros de convivência, entre outros. ${ }^{2}$

Os serviços substitutivos criados a partir da Reforma Psiquiátrica, organizados em torno dos princípios de desinstitucionalização e desospitalização, incluem a participação dos familiares no cuidado aos usuários numa articulação de corresponsabilidade. No entanto, ao assumirem responsabilidades, as quais antes pertenciam ao hospital psiquiátrico, os familiares vivenciam situações e sentimentos que são difíceis de elaborar e entender.

A complexidade de cuidar de uma pessoa em sofrimento mental e ao mesmo tempo o despreparo das famílias para tal atividade, direcionou os avanços nesta área para o entendimento do significado de sobrecarga familiar. Tal entendimento foi desenvolvido para definir as consequências negativas de cuidar do membro adoecido, abrangendo encargos econômicos, físicos e emocionais. ${ }^{3}$

$\mathrm{O}$ adequado suporte à família é um dos pilares da Reforma Psiquiátrica, em que o trabalho de reabilitação psicossocial é entendido como um processo que visa reabilitar e desenvolver novas atitudes e comportamentos na pessoa em sofrimento mental e, também, em seus familiares. Para atender esta proposta surgiram, dentre outros serviços, os CAPS. As ações desenvolvidas nestes serviços incluem atenção às pessoas em sofrimento mental e aos seus familiares, de forma a construir projetos de inserção social respeitando as capacidades de cada indivíduo e princípios de cidadania, potencializando maior qualidade de vida e inclusão social. ${ }^{3-4}$

Dentre as estratégias de atenção à família, o grupo de familiares é o mais referenciado por autores e utilizado na prática em saúde mental, visto que funciona como um espaço de acolhimento à emergência da experiência de vida de cada um de seus participantes. 0 que requer considerar a aplicabilidade e resultados consoantes à terapia com grupos familiares e a satisfação do familiar participante.

Diante do exposto, o presente estudo tem por objetivo compreender a diversidade de experiências dos familiares da pessoa em sofrimento mental dentro do grupo de familiares. 


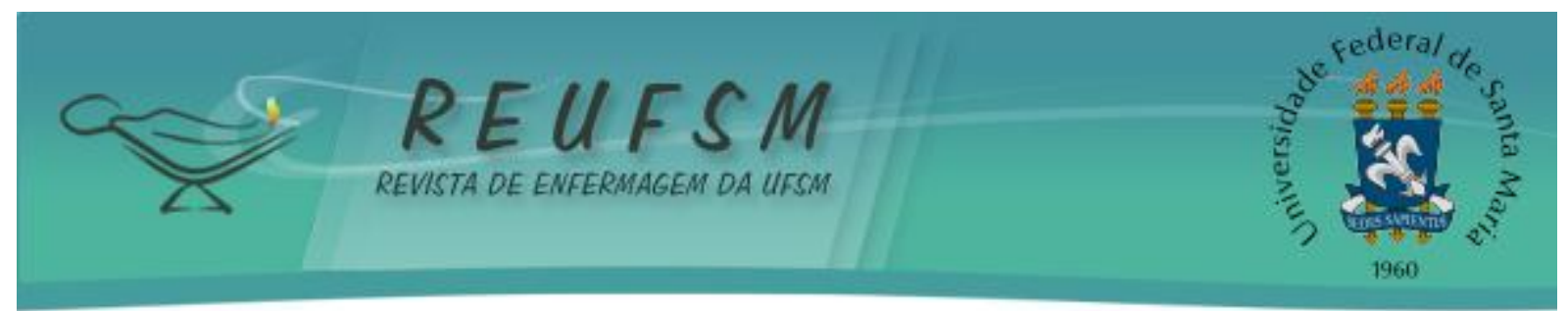

MÉTODO

Trata-se de um estudo qualitativo, exploratório e descritivo que foi desenvolvido em um CAPS de um Município de médio porte da Região Sul do Brasil. Esse CAPS foi criado em 2001 com o intuito de acolher pessoas em sofrimento psíquico grave, estimular sua integração social e familiar, apoiando-os em suas iniciativas de busca à autonomia. Os encontros ocorrem mensalmente, em dois momentos, na última terça-feira pela manhã e na última quinta-feira do mês, no período da tarde, havendo uma média de 10 participantes em cada grupo.

Os sujeitos do estudo foram cinco familiares que participavam do grupo de familiares do CAPS há pelo menos seis meses, selecionados mediante sorteio. Para garantir os princípios éticos de sigilo e anonimato, estes foram citados pelo codinome familiar 1 , familiar 2, sucessivamente. O Protocolo do Projeto foi aprovado pelo Comitê de Ética em Pesquisa com Seres Humanos da Universidade Federal de Pelotas sob o n²4/2009.

A coleta dos dados foi realizada no período de novembro e dezembro de 2009, através da aplicação de entrevistas semiestruturadas gravadas em aparelho digital (MP3), no domicílio dos participantes. Para tanto, foi realizado o agendamento das entrevistas conforme a disponibilidade dos familiares em receberem os pesquisadores em seu domicílio, bem como o prévio consentimento dos mesmos, expresso por meio da assinatura do Termo de Consentimento Livre e Esclarecido. Os dados provenientes das entrevistas foram transcritos na íntegra, lidos, analisados e agrupados em temáticas, identificando os depoimentos que responderam aos objetivos da pesquisa.

\section{RESULTADOS E DISCUSSÃO}

Ao considerar que o termo satisfação reflete uma multidimensionalidade, o estudo obteve uma pluralidade de dados que espelha a diversidade de experiências vivenciadas pelos familiares da pessoa em sofrimento mental dentro do grupo de familiares. Assim, a análise dos dados permitiu estabelecer as seguintes temáticas: operacionalização do grupo de familiares e satisfação dos usuários do grupo de familiares: potencialidades e limites.

\section{Operacionalização do grupo de familiares}

Para tornar adequada e saudável a convivência entre a pessoa em sofrimento mental e a família é necessária a oferta de uma assistência especializada que apóie, esclareça dúvidas e oriente nas dificuldades. Tais aspectos justificam a utilização da dinâmica de grupo no CAPS para o cuidado aos familiares de seus usuários. Esta estratégia inclui a participação dos familiares no cuidado aos usuários em uma articulação de corresponsabilidade. Traduz-se em cuidado à família no contexto da desinstitucionalização, pois oferta espaço à expressão de sentimentos, dúvidas e medos. ${ }^{5}$

0 grupo possui características que o constitui, não sendo um mero somatório de pessoas, mas uma entidade, com leis e mecanismos próprios e específicos, no qual todos os integrantes estão reunidos em torno de uma tarefa e de um objetivo comum. 0 tamanho do grupo não pode exceder ao limite que ponha em risco a indispensável preservação da comunicação. ${ }^{6}$

Dessa forma, além de possuir os objetivos claramente definidos, o grupo necessita levar em conta a preservação do espaço (os dias e o local certo das reuniões), do tempo (horários, tempo de duração das reuniões, plano de férias, dentre outras) e a combinação de regras e outras variáveis que delimitem e normatizem a atividade grupal proposta. ${ }^{6}$ 


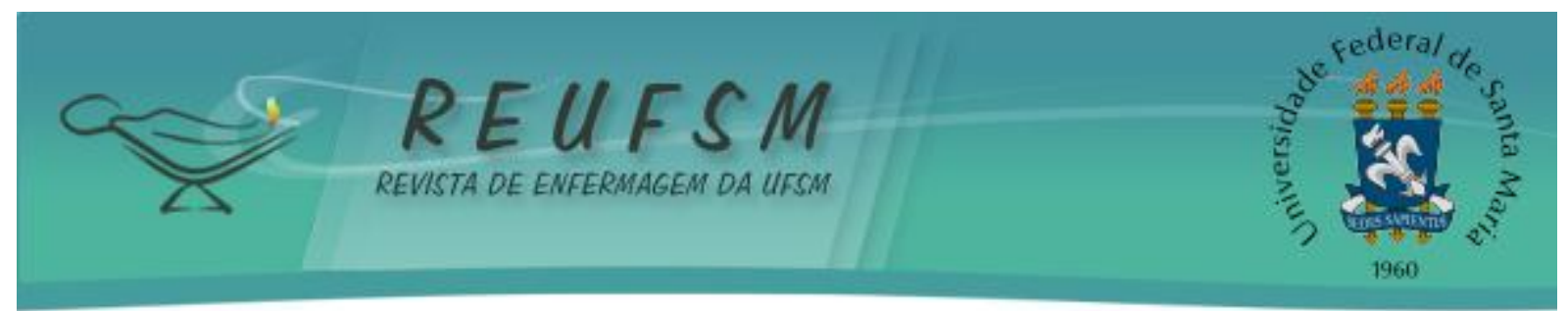

Os familiares ao descreverem o funcionamento do Grupo de Familiares evidenciaram a existência de organização, especificidade dos objetivos e a articulação entre os integrantes e o coordenador.

O grupo de familiares é assim: começa a reunião, as pessoas se apresentam: mãe de fulano, tu fala o teu nome e diz mãe de quem tu é, parente de quem tu é. Depois, tu fala como a pessoa está em casa e automaticamente tu já pergunta como que eles estão no CAPS. Está melhorando, não está melhorando. (Familiar 5)

Constata-se também a existência de uma distribuição hierárquica de posições e papéis, que embora distintos e intercambiáveis, se complementam entre si, tornando possível a existência do momento grupal.

O vínculo é construído a partir do compartilhamento do mesmo espaço e interesses, permeando a troca de angústias, medos e dúvidas, suscitando um ambiente acolhedor e de confiança. Local onde são tratados os assuntos considerados delicados e difíceis pelo familiar na convivência com a pessoa em sofrimento mental. ${ }^{7}$

Outro fato marcante quanto à existência do vínculo é a confiança do coordenador e profissionais pertencentes à equipe assistencial do CAPS dedicada aos familiares. Nos encontros grupais os profissionais obtêm informações sobre os usuários através dos familiares, havendo fidúcia acerca do conhecimento técnico científico da equipe no esclarecimento de dúvidas.

[...] quem está coordenando o trabalho vai perguntando como o familiar está se comportando, como tem passado em casa. Acredito eu, que para eles terem uma noção do que eles estão passando lá é o mesmo que em casa. E tirar dúvidas. Se tira muitas dúvidas. (Familiar 3)

Mediante a confiança, o vínculo constitui-se, estabelecendo-se como um recurso terapêutico, uma vez que, aproxima a família, o usuário e a equipe, favorecendo a comunicação e a troca de subsídios inerentes ao viver e conviver com uma pessoa em sofrimento mental. A comunicação é um aspecto importante na dinâmica grupal, pois representa a entrega e a doação de si. $^{8} \mathrm{E}$, também é o meio pela qual o integrante compartilha suas vivências no grupo e o coordenador ao exercer a escuta, fornece as orientações voltadas aos sentimentos e inquietações dos familiares, frente às dificuldades que se apresentam. Há o desencadeamento de um processo sucessivo de revelações quanto às potencialidades, como também, os limites do grupo, refletindo na satisfação do familiar com a prática assistencial.

Não obstante, a satisfação é um tema que requer atenção dos profissionais de saúde, quando o familiar é a fonte de informação para o planejamento de ações em prol da saúde mental de todos os envolvidos. Temática apresentada a seguir.

\section{Satisfação dos usuários do grupo de familiares: potencialidades e limites}

A difícil vivência da família que possui um dos seus integrantes em sofrimento mental pode ser contornada pelo cuidado. ${ }^{9}$ Cabe destacar que ao utilizar o grupo como proposta de cuidado terapêutico precisa-se estar atento à saúde dos seus integrantes. Os grupos terapêuticos estão voltados à saúde, tanto no que se refere ao plano orgânico quanto psíquico, atuando na atenção primária (promoção da saúde), como também na 


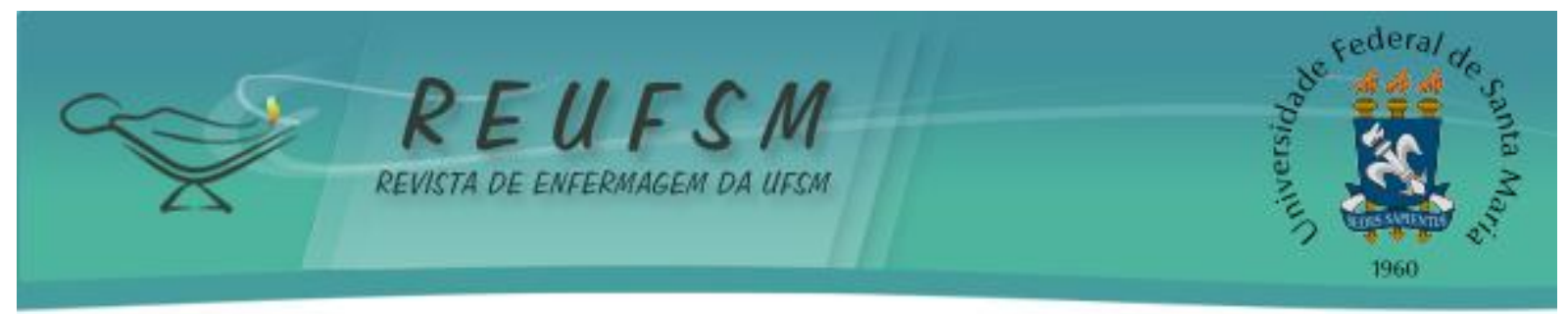

secundária (curativa) e na terciária (programas de reabilitação de pacientes portadores de alguma patologia ou deficiência crônica). ${ }^{6}$

Para oferecer cuidado com qualidade, que atenda as necessidades de cada familiar, se faz necessário um profissional que assuma o papel de coordenador. E que este, desenvolva com facilidade a capacidade de contato interpessoal, competência na interação e comunicação, preservando a autoestima através da empatia, respeito à individualidade e comportamento ético. ${ }^{9}$

Embora os familiares possuam experiências que por si só constituem-se em potencialidades, a oportunidade de expressar as vivências em um grupo, requer a presença de um coordenador, que saiba administrá-las com todo o arsenal terapêutico necessário. Assim, o coordenador age como um catalizador no processo de reconhecimento da realidade por parte do grupo, mas para isso ele deve fluir com o grupo, não se impondo à realidade, para não comprometer o livre curso grupal, em que as vivências se autorrevelam naturalmente. ${ }^{10}$

Quando a gente vai lá, novinha no grupo, na expectativa, e acha que o tratamento não está adiantando, é hora de quem está coordenando o trabalho explicar que é assim mesmo, que leva um tempo. Depois que a gente passa por isso sabe que leva um tempo. (Familiar 3)

O primeiro contato do familiar com o serviço de saúde mental, geralmente é marcado pelo desespero, especialmente pelas crises que a pessoa em sofrimento mental apresenta. Tal fato expõe o impacto do processo de desinstitucionalização, que ao mesmo tempo em que promove a convivência e a manutenção do vínculo, impõe à família sobrecarga de cuidar do seu ente em períodos de manifestação aguda, ou dos com quadros crônicos e residuais da doença. ${ }^{11}$

[...] quando é a primeira vez, e é assim com todos, a expectativa de melhora é muito grande, a gente quer tudo para ontem. 0 familiar vai lá no desespero. Isso é com todo mundo. Eu me lembro, não conheci a menina, mas eu lembro da primeira reunião que a irmã dela foi. Eu acredito que ela é uma menina bem jovem pelo que elas falavam, e aquilo me chamou atenção porque foi tudo que nós já tínhamos passado. (Familiar 3)

Estas convivências intensas em torno do sofrimento mental mobilizam os sujeitos na busca de alternativas. ${ }^{5}$ Um grupo coeso e bem constituído exerce a função de ser um continente às angústias e necessidades de cada um e de todos. ${ }^{6}$

Quando um familiar chega ao serviço procurando ajuda, deseja orientações, porque ele sozinho não está conseguindo encontrar uma saída para suas angústias e problemas no convívio com a pessoa em sofrimento mental. Então, sua expectativa é de encontrar uma figura que responda a todas as suas perguntas e que the indique soluções.

No grupo o coordenador, inicialmente, assume este papel e, sabiamente, vai colocando na dinâmica grupal as questões de pauta, em que os próprios familiares interagem argumentando, sugerindo e expondo suas experiências. 0 fato de estar envolvido na elaboração de "saídas" e de possuir respostas que tanto esperavam, contribui para o sentimento de satisfação.

Durante os momentos grupais, os familiares referiram haver necessidades diferentes entre eles, pois os níveis de atenção variavam. Um familiar falava de momentos de crise, outro perguntava sobre certo medicamento e um terceiro informava sobre a 


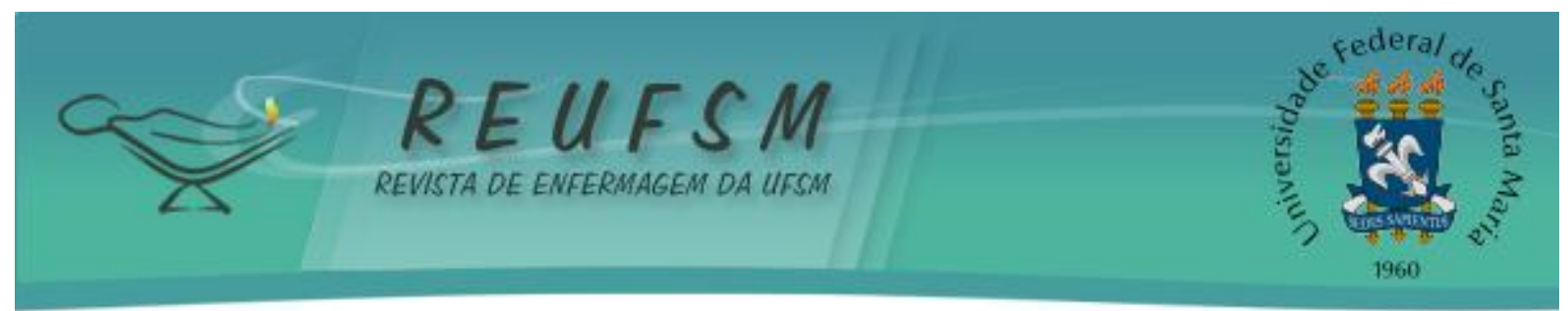

estabilidade do quadro clínico de seu familiar, perpassando por todas estas inquietações expostas pelo grupo. Apontamentos estes, expressos na fala a seguir:

[...] uns têm problemas a mais, outros têm umas queixinhas a menos, mas eu acho que é conforme o paciente. (Familiar 2)

Há um processo de conhecimento que os familiares demonstraram ter adquirido por suas vivências com a pessoa em sofrimento mental. ${ }^{12} \mathrm{Um}$ conhecimento sólido, constituído empiricamente no fazer o cuidado, que deve ser valorizado, pois está repleto de capítulos baseados na realidade, a seguir:

Eu levo alguma coisa que eu consigo fazer com ela em casa, que eu consigo que ela faça, e outros trazem as mesmas coisas, quando perguntam como é que eles andam em casa. E, um vai ajudando o outro. (Familiar 5)

O grupo é possuidor de vida própria e única, em que cada componente é um ser repleto de experiências, sentimentos e conhecimentos. ${ }^{13}$ Assim, ao ouvir outra pessoa que vive uma realidade semelhante, acende-se um campo ativo de identificações. 0 grupo se constitui como uma galeria de espelhos, onde cada um pode refletir e ser refletido nos e pelos outros, configurando-se em uma oportunidade de discriminar, afirmar e consolidar a própria identidade pessoal. ${ }^{6}$

O processo de identificação facilita aos participantes ver no outro o reflexo de sua própria realidade, aliviando a sensação de isolamento e solidão ${ }^{5}$, muito comum entre eles:

Observar que ele não é a única pessoa que têm problema, que outros também, e que levam uma vida normal. Porque a impressão que eu tinha é que ele era paciente, o único que tinha problema. (Familiar 3)

A experiência de grupo pode consistir em um campo multiplicador de experiências, no qual a identificação entre os integrantes tende a aumentar o grau de coesão e confiança. ${ }^{5}$ Cada integrante do grupo adota a direção que the seja mais adequada, dentro da sua realidade.

Tem muitas pessoas que tem as mesmas reações como ela tem, as mesmas explosões. Então, vamos supor, eu falo como eu ajo, da maneira que eu faço. A outra pessoa diz como é que também faz. Às vezes a gente troca ideias, porque eu posso não estar fazendo o certo. Porque, às vezes, a gente está batendo na mesma tecla e acha que não está adiantando. E, assim, às vezes, uma ideia surge. (Familiar 5 )

O familiar pensa e analisa o que está dizendo, comparando suas experiências e o seu comportamento com os demais. $E$ mesmo aquele que se mantém em silêncio, mas comparece regularmente nos encontros, pode estar engajado em seu propósito e processando as informações para promover a mudança que almeja. Assim é possível desenvolver a educação em saúde no grupo, valorizando o diálogo e a criação de um espaço à reflexão. ${ }^{14}$

0 fato de haver outros olhares para um mesmo problema proporciona alívio na tensão dos familiares, acalmando-os ao visualizar uma saída. 


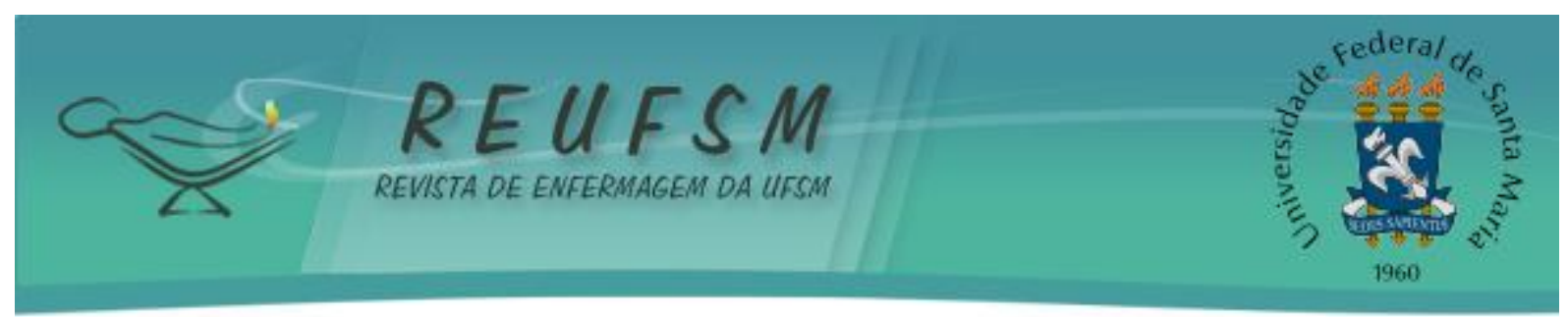

Porque tu acha que é só com ela, só ela que está fazendo isso, mas aí a gente lá, conversando, vê que tem gente com outro problema, diferente do dela, mas que faz igual. (Familiar 1)

São desenvolvidas alternativas, pelo coordenador, para o enfrentamento de ansiedade, fantasia, frustração, raiva, medo e outros sentimentos provenientes do usuário e seu familiar. Assim, a estratégia do trabalho em grupo busca atender, integralmente, ao familiar, trabalhando as manifestações decorrentes da doença. Isso ocorre através da oferta de informações sobre a psicopatologia, sinais e sintomas, psicofármacos, obtenção de medicamentos, manejo das crises, serviços específicos da rede do Sistema Único de Saúde (SUS), além dos benefícios governamentais.

Outra coisa que foi orientado lá, que eu consegui para ele, foi o benefício. Que foi uma reunião que teve lá com a assistente social do Instituto Nacional do Seguro Social (INSS) explicando tudo como a gente deveria fazer, e aí eu consegui para ele. Foi através de lá. Um benefício financeiro que para autoestima dele ajudou muito. (Familiar 3)

0 grupo coloca-se na qualidade de continente à medida que as angústias dos integrantes são identificadas e trabalhadas, e não apenas escutadas. Dessa forma, os participantes sentem que possuem um ponto de apoio, ao qual eles recorrem sempre que necessário.

A dinâmica grupal ajuda os familiares na compreensão de que os delírios, alucinações, agressividade e o embotamento afetivo fazem parte do adoecimento. ${ }^{15} \mathrm{~A}$ ação, na coletividade, instrumentaliza os familiares para o enfrentamento dos sintomas característicos da doença.

[...] ela passa fechada [isolada]. Falam que outro também passa fechado, ou só escrevendo, ou só vendo televisão. E eu fico sabendo que não é só ela, que tem mais gente que faz isso, que tem horas que só querem ficar isolados. (Familiar 1)

Cria-se então, a condição de pertencimento ao grupo, ou seja, o sentimento de que o familiar, de fato, pertence ao grupo do CAPS, é aceito e reconhecido pelos demais, e vice-versa. ${ }^{16}$ Este sentimento faz com que o familiar sinta-se engajado no grupo, sendo corresponsável pela construção de estratégias que satisfaçam as suas necessidades, bem como a da pessoa doente.

Assim, cada um sente que pode contar com o outro, de forma que a simples existência do grupo assegura a cada participante a sensação de possuir um novo "continente" que, muitas vezes, preenche o vazio de uma família:

Quando eu tenho muitas dúvidas, qualquer coisa, eu vou lá. Estou sempre lá pelo CAPS. (Familiar 5)

Além de todas as potencialidades, anteriormente citadas, o grupo possui ainda as vantagens econômicas na utilização do recurso grupal, tratando de várias pessoas ao mesmo tempo, com economia de tempo e de recursos humanos nos serviços. ${ }^{17}$ No entanto, os grupos constituem um domínio em que podem aparecer limitações. Uma delas é a dificuldade em trabalhar com conceitos cristalizados, como a incapacidade de obtenção de melhoras no cotidiano da pessoa em sofrimento mental: 


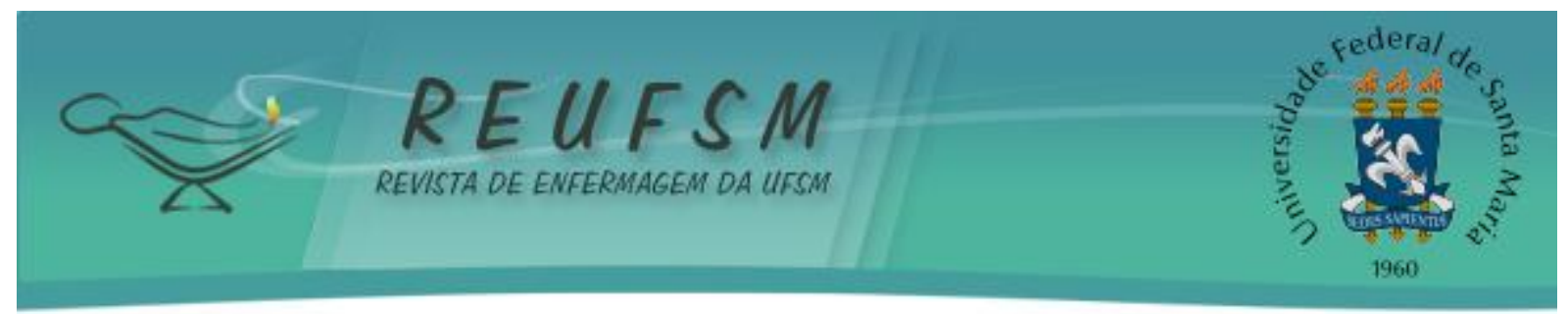

Tem uma mãe no grupo de familiares que ela é meio rígida para essas coisas, ela acha que nada vai ser bom. (Familiar 5)

Tal fato não pode ser resolvido de uma maneira simples, pois envolve a mudança de conceitos e preconceitos enraizados, suscitando uma transformação na maneira de pensar dos familiares. $\mathrm{O}$ alvo incide no respeito ao usuário, considerando as limitações do ser doente, e da própria sociedade. ${ }^{9}$

Outro limite encontrado refere-se à dificuldade de abordar certos assuntos intimamente ligados à vergonha.

Não é tudo que eu gosto de expor no grupo de familiares. Têm coisas, problemas dela, de higiene, que eu prefiro não falar. (Familiar 5)

Este aspecto leva a refletir acerca da existência dos limites pessoais e a importância de observá-los e respeitá-los, oferecendo suporte complementar.

Também se salienta o número reduzido de familiares que participam do grupo, fato que é sentido pelos próprios integrantes como fragilidade, conforme exposto a seguir.

Tinha que participar mais gente pelo número de usuários que tem no CAPS. Na reunião de familiares, muitas vezes, tu vê sempre as mesmas pessoas na reunião. (Familiar 5)

É importante [participar das atividades do CAPS], porque o familiar precisa estar a par do que está acontecendo com ele ali dentro. (Familiar 4)

A inadequação da linguagem utilizada é expressa como dificuldade do Familiar 4 em compreender as solicitações:

Às vezes elas dão algum papel para a gente que às vezes eu não entendo, porque eu não tenho estudo. Às vezes respondo uma pergunta que vem nas minhas ideias, outras eu não respondo porque eu não sei. (Familiar 4)

A comunicação ocupa lugar de destaque entre as dimensões da satisfação, assim, a clareza das informações, explicação sobre a patologia e o tratamento, elucidação de dúvidas, são privilegiadas na mensuração da satisfação. ${ }^{18}$ Cada vez mais a assistência através de grupos tem conquistado o seu campo de atuação, dada a eficácia para atingir objetivos ou realizar tarefas, obter harmonia, resolver conflitos e tensões. ${ }^{19} \mathrm{O}$ preparo da equipe é importante na assistência à família, de forma a acolhê-la e ajudá-la quando necessário, minimizando as dificuldades que se apresentam cotidianamente, atenuando o estresse, sem impor formas de cuidado. ${ }^{20}$

A percepção dos familiares vem sendo considerada como um importante indicativo na avaliação da qualidade em saúde mental ${ }^{21}$, potencializando a adequação do serviço. Então, cabe aos enfermeiros e demais profissionais de saúde, engajados na reforma psiquiátrica, ousarem de uma postura ética centrada no comprometido em oferecer um serviço de saúde com qualidade, de forma que a família tenha suas necessidades atendidas. ${ }^{9}$

Sob a satisfação, os familiares relataram concordância à prática assistencial, sendo as expectativas, em sua maior parte, atendidas. Há o sentimento de fazerem parte do tratamento de seus entes doentes, sendo importantes neste processo. 


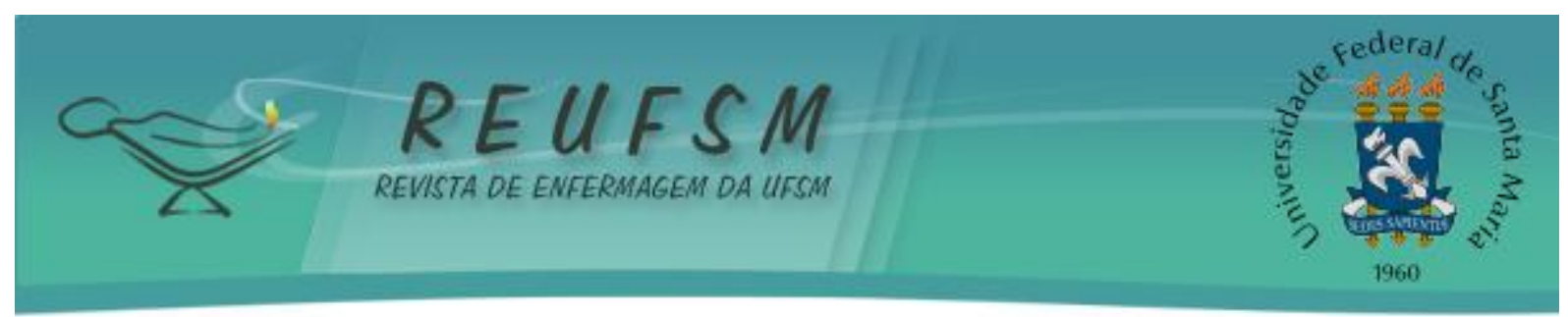

Eu estou muito satisfeita. É muito bom. É muito importante para a gente e para eles saberem que a gente vai ao grupo. É importante para a gente saber como que eles estão lá dentro, como está sendo o tratamento. E para eles, quando a gente vai, se sentirem importantes, não se sentirem atirados. [...] Participando a gente está demonstrando o interesse que tem pela vida deles. (Familiar 3)

A sensação do grupo de familiares quanto à satisfação diante do apoio recebido pelos profissionais de saúde no CAPS, viabiliza a esperança de uma vida mais dirigida às reais necessidades do familiar em sofrimento mental. Assim, quanto mais conectados estiverem os profissionais e a família deste, mais próximos todos estarão de um convívio saudável.

\section{CONCLUSÃO}

Os serviços substitutivos incluem a participação dos familiares no cuidado aos usuários em uma articulação de corresponsabilidade, que antes pertencia ao hospital psiquiátrico. São vivenciados sentimentos e emoções que são difíceis de elaborar e entender, assim, para atender a estas necessidades alguns serviços têm investido nos grupos. Fato que incentivou a realização do estudo, priorizando a voz dos familiares, sujeitos implicados na atenção psicossocial dos usuários no CAPS.

Os familiares entrevistados pedem escuta, acolhimento e ajuda para administrar a convivência com a pessoa em sofrimento mental. A oferta do Grupo de Familiares é como um valioso instrumento capaz de dinamizar o cuidado, otimizando a troca de saberes entre os familiares, auxiliando em seus anseios e capacitando-os para o convívio com a pessoa em sofrimento mental. A dinâmica grupal amplia as possibilidades de uma assistência mais digna e global, atuando em direção das transformações que se fazem necessárias na relação entre profissionais de saúde mental, os usuários e famílias. No entanto, salienta-se que tal prática é realizada com pessoas que estão, em sua maioria, fragilizadas, que apostam em soluções e que buscam uma melhor qualidade de vida nas atividades do grupo. Por isso, requer preparo específico do profissional, como forma de melhor aproveitar as potencialidades da dinâmica de grupos, como também, dos familiares, na assistência à pessoa em sofrimento mental.

É impossível negar a contribuição do trabalho com grupos, porém contar apenas com esse recurso para lidar com a emergência de sentimentos e emoções dos familiares pode trazer dificuldades tanto para os usuários quanto para o serviço, no cotidiano junto à pessoa em sofrimento mental. 0 ideal é que o CAPS disponha de uma diversidade de estratégias para dar conta das mais variadas necessidades, de acordo com a individualidade do usuário e sua família.

Como limitação deste estudo tem-se a abordagem de familiares de apenas um CAPS, o que impossibilita a generalização dos resultados. Porém, potencializa-se um movimento de reflexão sobre a práxis dos profissionais de saúde mental e a melhoria na qualidade dos serviços oferecidos nesse contexto.

\section{REFERÊNCIAS}

1. Amarante PDC. $O$ homem e a serpente: outras histórias para a loucura e a psiquiatria. $3^{\mathrm{a}}$ ed. Rio de Janeiro: Editora Fiocruz; 2008.

2. Brasil. Ministério da Saúde. Secretaria de Atenção à Saúde. Departamento de Ações Programáticas Estratégicas e Departamento de Atenção Básica. Saúde mental e atenção básica: o vínculo necessário: inclusão das ações de saúde mental na atenção básica.

Brasília: Ministério da Saúde; 2003. 


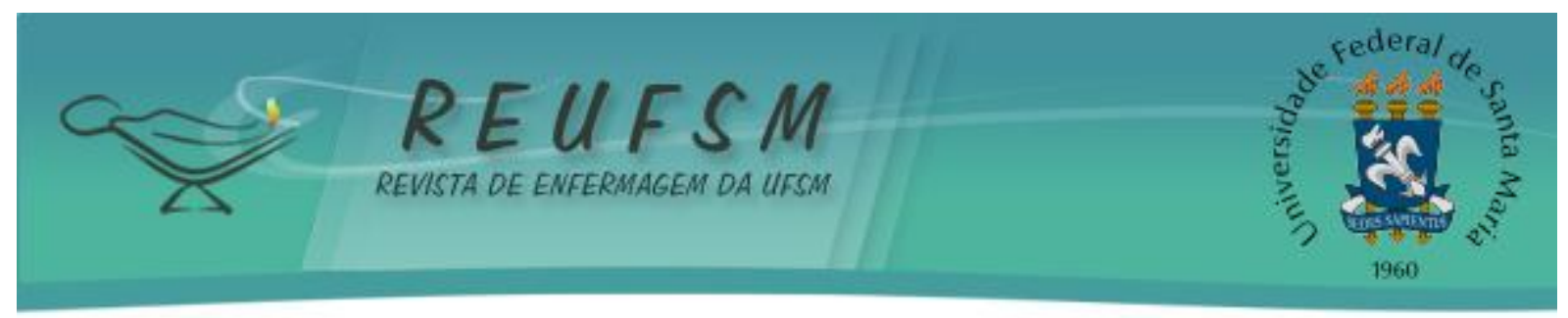

3. Borba LO, Schwartz E, Kantorski LP. A sobrecarga da família que convive com a realidade do transtorno mental. Acta Paul Enferm [internet]. 2008 [acesso em 2011 ago 12];21(4):588-94. Disponível em: http://www.scielo.br/pdf/ape/v21n4/a09v21n4.pdf.

4. Brasil. Ministério da Saúde. Secretaria de Atenção à Saúde, Departamento de Ações Programáticas Estratégicas. Saúde mental no SUS: os centros de atenção psicossocial. Brasília: Ministério da Saúde; 2004.

5. Melman J. Família e doença mental: repensando a relação entre profissionais de saúde e familiares. $2^{\mathrm{a}}$ ed. São Paulo: Escrituras; 2006.

6. Zimerman DE. A importância dos grupos na saúde, cultura e diversidade. Vínculo. 2007 dez;4(4):1-16.

7. Zimerman DE, Osório LC, colaboradores. Como trabalhamos com grupos. Porto Alegre: Artes Médicas; 1997.

8. Osório LC. Grupos: teorias e práticas acessando a era da grupalidade. $1^{\text {a }}$ ed. Porto Alegre: Artes Médicas; 2000.

9. Waidman MAP, Elsen I. O cuidado interdisciplinar à família do portador de transtorno mental no paradigma da desinstitucionalização. Texto \& Contexto Enferm [internet]. 2005 jul-set [acesso em 2011 jun 15];14(3):341-49. Disponível em:

http: //www.scielo.br/scielo.php?script=sci_arttext\&pid=S0104-07072005000300004\&lng=pt.

10. Macedo SM. Grupo e instituição: relações de poder na dialética de um processo grupal de aprendizagem. Estud Psicol. (Campinas). 1998 maio-ago;15(2):45-57.

11. Cavalheri SC. Transformações do modelo assistencial em saúde mental e seu impacto na família. Rev Bras Enferm [internet]. 2010 jan/fev [acesso em 2011 ago 22];63(1):51-7. Disponível em: http://www.scielo.br/pdf/reben/v63n1/v63n1a09.pdf.

12. Pereira MAO, Pereira Junior A. Transtorno mental: dificuldades enfrentadas pela família. Rev Esc Enferm USP [internet]. 2003 [acesso em 2011 ago 24];37(4):92-100.

13. Munari DB, Ribeiro V, Lopes MM. Intervenção grupal com enfoque no cuidado emocional: relato de experiência. Rev Bras Enferm. 2002 jul/ago;55(4):449-51.

14. Rodrigues MGS, Gomes VLO, Kantorski LP. Um processo de educação em saúde desenvolvido com um grupo de mães de crianças com algum grau de desnutrição. Texto \& Contexto Enferm. 2000 maio/ago;9(2):169-77.

15. Conejo SH, Colvero LA. Cuidado à família de portadores de transtorno mental: visão dos trabalhadores. REME Rev Min Enferm. 2005 jul/set;9(3):206-11.

16. Zimerman DE. Fundamentos básicos das grupoterapias. 2a ed. Porto Alegre: Artmed; 2000.

17. Maximino VS. A constituição de grupos de atividades com pacientes graves. Rev Ter Ocup. 1995;1(1):27-32.

18. Williams B, Coyle J, Healy D. The meaning of patient satisfaction: An explanation of high reported levels. Soc Sci Med.1998 Nov 47(9):1351-59. PubMed PMID: 9783878.

19. Andalo CSA. O papel de coordenador de grupos. Psicol. USP. 2001;12(1):135-52.

20. Waidman MAP, Stefanelli MC. Comunicação e estratégias de intervenção familiar. In: Stefanelli MC, Carvalho EC, organizadores. A comunicação nos diferentes contextos da enfermagem. Goiânia: Manole; 2005. p.118-37. 


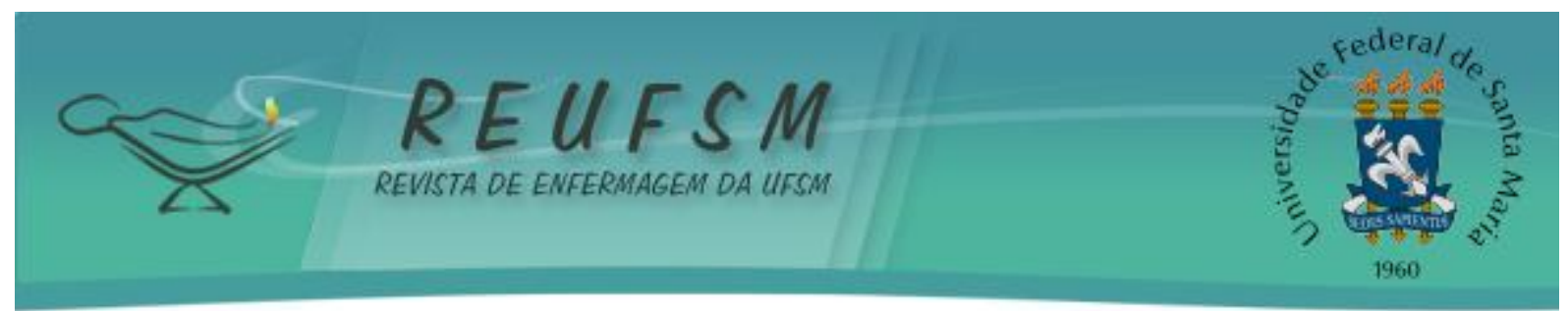

21. Bandeira M, Pitta AMF, Mercier C. Escalas da OMS de avaliação da satisfação e da sobrecarga em serviços de saúde mental: qualidades psicométricas da versão brasileira. J Bras Psiquiatr. 1999;48(6):233-44.

Data de recebimento: 07/01/2012

Data de aceite: 18/04/2012

Contato com autor responsável: Juliane Portella Ribeiro

Endereço: Rua Gonçalves Chaves, 65, Bl. A, Ap. 404. Centro. Pelotas, RS, Brasil. CEP: $96015-560$

E-mail: ju_ribeiro1985@hotmail.com 